\title{
CIRJE-F-602 \\ Impact of Natural Disasters on Industrial Agglomeration: The Case of the 1923 Great Kanto Earthquake
}

\author{
Tetsuji Okazaki \\ University of Tokyo \\ Kaori Ito \\ Tokyo University of Science \\ Asuka Imaizumi \\ Graduate School of Economics, University of Tokyo
}

November 2008; Revised in October 2009 and June 2011

CIRJE Discussion Papers can be downloaded without charge from:

http://www.cirje.e.u-tokyo.ac.jp/research/03research02dp.html

Discussion Papers are a series of manuscripts in their draft form. They are not intended for circulation or distribution except as indicated by the author. For that reason Discussion Papers may not be reproduced or distributed without the written consent of the author. 


\title{
Impact of Natural Disasters on Industrial Agglomeration: The Case of the 1923 Great Kanto Earthquake
}

\author{
Tetsuji Okazaki (The University of Tokyo)* \\ Kaori Ito (Tokyo University of Science) \\ Asuka Imaizumi (Saitama University)
}

\begin{abstract}
One of the main implications of the New Economic Geography, developed since the $1990 \mathrm{~s}$, is that a temporary shock can create a persistent impact on the geographic distribution of economic activities because of multiple equilibria. This paper investigates the long-run impact of a temporary shock on the geographic distribution of industries in Tokyo Prefecture, Japan, using the Great Kanto Earthquake in 1923 as a natural experiment. It is revealed that the temporary shock from the Great Kanto Earthquake was basically dissipated by 1936, just before the full-scale war with China broke out. On the other hand, through industry-level investigation, it is found that with respect to the machinery and metal industry, the impact was persistent and remained even in 1936. These findings suggest the importance of the industrial structure and transaction networks within industry in the mechanism determining geographic distribution of industries.
\end{abstract}

JEL classification: R11, R12, N95

Key Words: Industrial agglomeration, Clustering, Economic Geography, Natural disaster, Economic History, Japan

*okazaki@e.u-tokyo.ac.jp

The earlier version of this paper was presented at the World Economic History Congress at Utrecht University in 2009, Annual Meeting of Socio-Economic History Society in 2009, and seminars at Hitotsubashi University and Australian National University. We are very grateful for helpful comments by Professor Reiko Aoki, Yutaka Arimoto, Maartin Bosker, Yusaku Horiuchi, Peter Howlet, Takashi Kurosaki, Tomohiro Machikita, Chiaki Moriguchi, Kentaro Nakajima, Meg Sato, Kaoru Sugihara and other participants of those meetings and seminars. All remaining errors are auhors' responsibility. 


\section{Introduction}

One of the most important innovations in economics since the 1990s is the development of the New Economic Geography (NEG). The NEG models the endogenous mechanism of various geographical phenomena, including urbanization and industrial agglomeration. ${ }^{1}$

The NEG has stimulated empirical studies to test its implications, one of which is that a temporary shock can create a persistent impact on the geographic distribution of economic activities because of multiple equilibria. Several studies have examined this proposition by studying the temporary shocks created by wars.

Davis and Weinstein focused on the growth of cities in Japan after the bombing during the World War II. ${ }^{2}$ It was found that the destruction that resulted from the bombing did not produce a long-run impact on city growth in Japan, which means that multiple equilibria were not supported. They then proposed a more direct test on multiple equilibria, which they applied to the Japanese bombing data, and once again found no support for multiple equilibria. ${ }^{3}$

Following Davis and Weinstein, Brakman et al. investigated the impact of World War II bombing on the growth of German cities, and found that the bombing created a temporary, but not persistent impact on city growth in Germany. ${ }^{4}$ Meanwhile, Miguel and Roland focused on the effects of the bombing that took place during the Vietnamese War, and found that the bombing did not produce a long-run impact. ${ }^{5}$ These studies are basically negative to the existence of multiple equilibria, but recently Bosker et al. applied the direct test for multiple equilibria by Davis and Weinstein to the German bombing data to obtain positive evidence. ${ }^{6}$

This paper aims to contribute to this literature in three ways. First, the focus is on the effects of a natural disaster rather than the effects of a war for a temporary shock. The 1923 Great Kanto Earthquake that devastated Tokyo is the natural disaster selected for this study. As the bombings were "strategic," they may not have been completely exogenous. On the other hand, an earthquake is completely exogenous, and is considered to be a natural experiment in a narrow sense. In addition, as shown below, the shock of the Great Kanto Earthquake was extremely large. Second, ward- and county-level data of Tokyo Prefecture are used. The preceding literature that focuses on a temporary shock rejected the possibility of a long-run impact of a temporary shock, based on nationwide, city-level or district-level data. ${ }^{7}$ However, even if the nationwide geographic distribution of the population and economic activities are determined by the fundamental conditions and, hence, a temporary shock has no long-run impact, it is possible that a temporary shock gives a long-run impact within a more limited area. In such a case, the variation of fundamental conditions, such as proximity to the coast and river, are supposed to be smaller, hence the existing equilibrium of geographic distribution of economic activities within it is less stable. In addition, the case of the Great Kanto Earthquake is useful to identify the shift of equilibrium, because not only

1 Fujita et al., The Spatial.

2 Davis and Weinstein, "Bones."

3 Davis and Weinstein, "A Search."

4 Brakman et al., "The strategic."

5 Miguel and Roland, "The long run."

6 Bosker et al., "Looking for."

7 On the other hand, Redding et al. found that division of Germany after WWII, which was supposed to be permanent, shifted the location of the airport hub from Berlin to Frankfurt even after the reunification of West and East Germany. The effect of a permanent border change is also found by Nakajima in the case of independence of Korea from Japan in 1945 (Nakajima, "Economic.") 
did those fundamental natural conditions not change due to the earthquake, but the physical infrastructure, including public transportation, also recovered swiftly after the earthquake. ${ }^{8}$ Third, the industry-level impact of the earthquake is observed. As the technologies and industrial structures were different across industries, any long-run impacts of the temporary shock may differ across industries.

The remainder of the paper is organized as follows. Section 2 describes the damage caused by the Great Kanto Earthquake, and the subsequent reconstruction policy. Section 3 describes the changes seen over time in the geographic distribution of industries in Tokyo Prefecture. Section 4 econometrically analyses the long-run impact of the earthquake on industrial agglomeration. Section 5 concludes the paper.

\section{The Great Kanto Earthquake and Reconstruction}

At 11:58 am on September 1, 1923, a huge earthquake with a magnitude of M 7.9 hit the southern area of the Kanto district in Japan. This earthquake, the Great Kanto Earthquake, was the worst natural disaster in the history of Japan. The damage extended over seven prefectures: Tokyo, Kanagawa, Saitama, Chiba, Ibaraki, Shizuoka, and Yamanashi, centering on Tokyo and Kanagawa. The total number of deaths and missing persons was more than $100,000,{ }^{9}$ which was 16 times greater than the losses from the 1995 Kobe Earthquake. In addition, more than 460,000 buildings were completely burnt or destroyed. 10 The human and physical damage was concentrated in the prefectures of Tokyo and Kanagawa (Table 1, Table 2, Figure 1, Figure 2). The main reason for such a large amount of damage was the great fire caused by the earthquake. While the fire itself generated strong winds, the destruction of the water supply system caused by the earthquake severely impeded the fire-fighting capability, which, in turn, resulted in tremendous fire damage. ${ }^{11}$

\section{Table 1, Table 2, Figure 1, Figure 2}

It is notable that within Tokyo Prefecture there was substantial variation in the damage. At the time, Tokyo Prefecture was composed of Tokyo City and eight counties. ${ }^{12}$ Tokyo City, in turn, was composed of 15 wards. Figure 2 indicates the burnt ratio (the number of buildings completely burnt or destroyed divided by the total number of buildings just before the earthquake) by city and county in Tokyo Prefecture. As can be seen, the damage was concentrated on Tokyo City, in the southeast part of Tokyo Prefecture. Of the 15 wards of Tokyo City, those that were located in the east part of the city were most seriously damaged. Indeed, in the six wards ${ }^{13}$ in that part, burnt ratios were higher than $80 \%$ (Figure 3).

\section{Figure 3}

8 Railways were seriously damaged by the earthquake, but by October 1923, most of the major railway lines were reconstructed by the activities of the engineer brigade (Social Affairs Bureau, Ministry of Home Affairs, Taisho, pp. 439-441). The Yokohama Port was also reconstructed by 1925 (Society for Research on the Recovery, Teito, p. 2123).

9 Here, the number of deaths and missing persons include those who died from the quake itself and those who died from the fire caused by the earthquake.

10 Here, "destroyed" refers to "directly destroyed by the quake," while "burnt" refers to "burnt by the fire caused by the earthquake."

11 Tokyo City Government, Teito, p. 28.

12 Besides them, there was a small city, Hachioji City, as well as islands. In 1932, Tokyo

City merged five counties and reorganized them into twenty new wards.

13 These wards are Kanda, Nihonbashi, Kyobashi, Asakusa, Honjo, and Fukagawa. 
The Tokyo City Government estimated the total amount of the physical damage in the seven prefectures (Table 3). According to the estimation, a large part of the damage consisted of commodities, buildings, and household goods. The total amount of the damage was 5,506 million yen, which is equivalent to 6,168 billion yen (65.6 billion dollars) at 1995 prices, ${ }^{14}$ when the Kobe Earthquake occurred. This is $62.1 \%$ of the damage caused by the Kobe Earthquake, ${ }^{15}$ but in terms of the percentage of GNP (GDP), the damage caused by the Great Kanto Earthquake was far greater than the damage caused by the Kobe Earthquake. That is, while the ratio of the Kobe Earthquake damage to GDP in 1994 was 2.1\%, the ratio of the Great Kanto Earthquake damage to GNP in 1922 was $35.4 \% .^{16}$

We can also compare the magnitude of the damage from the Great Kanto Earthquake with that from World War II, on which Davis and Weinstein focused. ${ }^{17}$ According to the estimation by the Economic Stabilization Board, the total amount of physical damage was 4,245 billion yen at 1948 prices, ${ }^{18}$ which is equivalent to 33,505 billion yen (356 billion dollars) at 1995 prices. The ratio of the war damage to GNP in 1940 is $108.5 \%{ }^{19}$ This ratio is around three times larger than that of the Great Kanto Earthquake. However, it should be remembered that the damage of the Great Kanto Earthquake concentrated on Tokyo Prefecture and Kanagawa Prefecture. Indeed, the ratio for Tokyo Prefecture in terms of buildings completely destroyed or burnt by the earthquake was 39.8\%, while the equivalent ratio for the World War II was 31.4\% (Table 2, Economic Stabilization Board, p. 344). In this sense, with respect to Tokyo Prefecture, the damage from the Great Kanto Earthquake matched that from World War II.

Table 3

Just after the Great Kanto Earthquake, the government began to draw up a reconstruction plan. A new government agency that was to be in charge of the plan, the Agency of Imperial Capital Reconstruction (Teito Fukko-in), was established in September 1923. However, because of the pressure on the Diet to reduce expenditures, the governmental draft plan was curtailed, and the Agency of Imperial Capital Reconstruction was abolished in 1924. It was succeeded in its role by the Bureau of Reconstruction, which was newly established in the Ministry of Home Affairs, and a reconstruction project was implemented. A distinctive feature of the reconstruction plan was that it was drawn up as a part of the city plan. The City Planning Law and the City Area Architecture Law had been already legislated in 1919, ${ }^{20}$ and, in accordance with these two laws, the government had prepared a city plan for Tokyo before the

14 To convert the 1923 values to 1995 values, we used a series of deflators, linking the GNP(GDP) deflators of Ohkawa et al., Kokumin Shotoku, the Economic Planning Agency, Kokumin Shotoku, and the Economic Planning Agency, Kokumin Keizai.

15 According to the estimation by Hyogo Prefecture, the total amount of damage caused by the Kobe Earthquake was 9,927 billion yen (webpage of Kobe News Paper, http:// www.kobe-np.co.jp/sinsai/kiroku/higai0012.html).

16 Nominal GNP in 1922 was 15,573 million yen (Ohkawa et al., Kokumin Shotoku).

17 Davis and Weinstein, "Bones"; and "A search."

18 Economic Stabilization Board, Taiheiyo. The original Japanese name of the agency was Keizai Antei Honbu. Although Davis and Weinstein refer to it as the Central Economic Stabilization Board ("Bones"), here we use the official English name.

19 The war damage at 1940 prices was 42.76 billion yen, while the nominal GNP in 1940 was 39.40 billion yen (Economic Planning Agency, Kokumin Shotoku).

20 Ishida, Nihon, pp. 114-143; and Koshizawa, Tokyo, pp. 13-23. 
earthquake, but it was not implemented. This city plan was then incorporated to be implemented in the reconstruction plan. ${ }^{21}$

It is notable that the city plan included zoning regulations. ${ }^{22}$ The City Area Architecture Law prescribed three categories of zones: the residential zone, the commercial zone, and the industrial zone. With respect to factories, the following regulations were imposed in these zones. ${ }^{23}$ In a residential zone, factories using motors of greater than $3 \mathrm{hp}$ were prohibited, whereas in a commercial zone, factories using motors of greater than $15 \mathrm{hp}$ were prohibited. In addition, a factory that had dangers or inconveniences such as a risk of explosion, discharging harmful or pungent gases or liquids, discharging a significant amount of dust, or generating noise or vibrations, was prohibited in both residential and commercial zones. With respect to industrial zones, factories were identified that could only be allowed in that zone. A factory using motors of greater than $50 \mathrm{hp}$ or a factory with one of the above dangers or inconveniences was only allowed in an industrial zone. Besides these three zones, there was also a "zone not yet specified." In this zone, a factory using motors of $50 \mathrm{hp}$ or less was allowed. For Tokyo City, zoning was determined in 1925 and revised in both 1929 and 1935.24 In evaluating the long-run impact of an earthquake on industrial growth, control and the effects of zoning should be considered.

\section{Impact of Earthquake on Industrial Agglomeration within Tokyo}

Next, we focus on the impact of the earthquake on industries within Tokyo Prefecture. Table 4 details the changes over time in the distribution of industries. The shares of industrial workers to the total number of industrial workers in Tokyo Prefecture are indicated for the fifteen wards of Tokyo City, and for the five neighboring counties, which were merged into Tokyo City in 1932.

First, it can be seen just how large the temporary shock of the Great Kanto Earthquake was. The total number of workers declined by 35\% from 1922 to 1923. Second, the shock varied substantially across wards and counties. Four wards in the southeast downtown area, Kanda, Kyobashi, Honjo, and Fukagawa, were extremely damaged. These wards had been an agglomeration area of industries before the earthquake, but they lost more than $50 \%$ of their shares of industrial workers. On the other hand, the shares of counties increased substantially. In this sense, the earthquake changed the geographic distribution of industries in Tokyo Prefecture substantially, at least temporarily. Finally, it is notable that a part of this change seems to have been persistent. In the four wards that were seriously damaged, more than half of the decline in the shares from 1922 to 1923 still remained in 1936, even though the Japanese economy had passed through the Great Depression and the rapid growth of the 1930s. ${ }^{25}$

\section{Table 4}

Table 5 shows the shares of industrial workers by ward and county with respect to the two largest industries in Tokyo, namely the textile industry and the machinery and metal industry. The great magnitude of the temporary shock and its persistence are also observed in the data from the individual industries. Another interesting

21 Takebe, Teito, pp. 44-45; and Tokyo City Government, Shinsai, p. 94.

22 This was the first time zoning had been implemented in Tokyo City.

23 Yano, Kojo, pp. 40-172. The regulations were revised several times. The following was the regulation in 1932 .

${ }^{24}$ Horiuchi, Toshi, pp. 56-70.

25 Concerning the macroeconomy in Japan in this period, see Nakamura, Economic Growth and Cha "Did Korekiyo." 
observation is that the persistence seems to be stronger for the machinery and metal industry than for the textile industry. With respect to the textile industry, the share of workers declined by more than 50\% from 1922 to 1923 for seven wards, but for four of the wards, more than half of the decline had been recovered by 1936. On the other hand, with respect to the metal and machinery industry, the shares of workers declined more than 50\% from 1922 to 1923 for three wards, and more than half of the decline still remained in 1936 for two of them.

\section{Table 5}

\section{Testing the persistence of the impact}

Observations in the previous section suggest that the Great Kanto Earthquake might have a persistent impact on the geographic distribution of industries. We now examine the persistence quantitatively. For this purpose, we first employ the interrupted time series analysis. ${ }^{26}$ We estimate the following equation:

SHARE $_{\mathrm{rt}}=\alpha \mathrm{X}_{\mathrm{r}}{ }^{*}$ AFTER $_{\mathrm{t}}+\beta \mathrm{X}_{\mathrm{r}}{ }^{*}$ QUAKETREND $_{\mathrm{t}}+\delta_{\mathrm{r}}+\gamma_{\mathrm{r}}$ BASETREND $_{\mathrm{t}}$

The dependent variable, SHARE $\mathrm{rt}$, represents the share of ward or county $\mathrm{r}$ of the total workers in Tokyo Prefecture in year t. We basically decompose it into two items, namely share levels specific to individual wards and counties $\left(\delta_{\mathrm{r}}\right)$ and time trends specific to individual wards and counties $\left(\gamma_{\mathrm{r}} \mathrm{BASETREND}_{\mathrm{t}}\right)$. BASETREND $\mathrm{t}$ is the time trend. In addition, we assume that the Great Kanto Earthquake shifted the share level $\left(\alpha \mathrm{X}_{\mathrm{r}}{ }^{*}\right.$ AFTER $\left._{\mathrm{t}}\right)$ and the slope of the trends $\left(\beta \mathrm{X}_{\mathrm{r}}{ }^{*} \mathrm{QUAKETREND} \mathrm{t}_{\mathrm{t}}\right)$. Here, $\mathrm{X}_{\mathrm{r}}$ is the indicator of the damage done by the Great Kanto Earthquake in ward or county $r$. In other words, it is assumed that the shift of the share levels and slope of the trends were proportionate to the magnitude of the damage. AFTER $\mathrm{t}$ is the dummy variable that equals 1 for years from 1923 onward, and 0 otherwise. QUAKETRENDt is the time trend that equals 0 until 1923 and then 1, 2, 3, etc., to the end of the time series.

SHARE $_{\text {rt }}$ is calculated from the data obtained from the various issues of the Statistical Yearbook of Tokyo Prefecture (Tokyo-fu Tokeisho). This source provides the total number of industrial workers employed by private factories by ward and county for 1917, 1919, and 1921-1936. The year 1936 was just before the Sino-Japanese War broke out, and after that, the government intervened extensively in the economy. ${ }^{27}$

For $\mathrm{X}_{\mathrm{r}}$, we use the ratio of completely broken or burnt buildings $\left(\mathrm{BROKEN}_{\mathrm{r}}\right)$, the ratio of burnt areas $\left(B U R N_{r}\right)$, and the ratio of the number of deaths and missing people $\left(\mathrm{DEATH}_{\mathrm{r}}\right)$. BROKEN $\mathrm{r}$ and $\mathrm{DEATH}_{\mathrm{r}}$ are taken from the report by the Ministry of Home Affairs, and $\mathrm{BURN}_{\mathrm{r}}$ is taken from a book by a newspaper company. ${ }^{28} \mathrm{In}$ addition to these explanatory variables, we add a policy variable. As described in Section 2, as a part of the reconstruction plan, in 1925 the government implemented area zoning, which had been prepared before the earthquake. As the zoning is considered to affect the geographic distribution of industries, we want to control for this effect. In order to make a zoning variable, we measure the area of each zone in each ward and county by processing a printed city-planning map and combining it with a digital map found in a database using Geographic Information Systems (Figure 4). ${ }^{29}$ The result of the

${ }^{26}$ Interrupted time series analysis is a popular methodology for policy evaluation in the field of political science in particular. See, for example, Anderton and Carter "The impact" and Evans et al., "The impact."

27 Okazaki and Okuno-Fujiwara eds., Contemporary.

28 Ministry of Home Affairs, Shinsai; Chugai Shogyo Shinpo-sha, Zuroku.

29 Concerning this procedure, see the Appendix. 
measurement is reported in Table 6. From this table, we make a variable, AREAI , that denotes the ratio of the industrial area to the total area of each ward or county. The basic statistics of the variables are summarized in Table 7 .

Figure 4

Table 6

Table 7

The estimation results are presented in Table 8. In this table, area dummies and area-specific time trends are not reported, although they are included in the model. The earthquake damage robustly shifted the level of the worker share, as indicated by the negative coefficients of the interaction terms of damage variables and AFTER. Meanwhile, it is notable that the magnitude of the level effect is not so large. Given the coefficients and the basic statistics, we can say that a one standard deviation change in the damage variables is estimated to result in only about a $0.05-0.11$ standard deviation change in SHARE. Furthermore, the damage had a positive impact on the slope of the share trend. The coefficients of the interaction term of the damage variable and QUAKETREND are positive and statistically significant. Comparing the magnitude of the level effect and slope effect, we can conclude that the negative level effect was cancelled by the positive trend effect within four years. In columns (4) and (5) of Table 8, we control for the zone variable (AREAI). It is noted that the results are qualitatively the same. Although we want to examine the difference in persistence of the impact across industries, sufficiently long time series data on workers are not available by industry. Hence, we address this issue by another methodology, namely the unit-root test employed by Davis and Weinstein and Brakman et al. ${ }^{30}$

Table 8

We model the logarithms of the shares of the total manufacturing workers in different areas in different years as follows:

$$
S_{r t}=\Omega r+\varepsilon_{r t},
$$

where $S_{r t}, \Omega_{r}$, and $\mathcal{E}_{r t}$ denote the log worker share of area $\mathrm{r}$ in year $\mathrm{t}$, the log initial worker share of area $r$, and the area-specific shock in area $r$ in year $t$, respectively. The persistence of the shock is modeled as:

$$
\varepsilon r t+1=\rho \varepsilon r t+v_{r t}+1,
$$

where $v_{r t}$ is the innovation that is assumed to be distributed identically and independently. ${ }^{31}$ By first differencing equation (2) and by using equation (3), we obtain:

$$
S_{r t+1}-S_{r t}=(\rho-1) v_{r t}+\left[v_{r t}+1+\rho(1-\rho) \varepsilon_{r t}-1\right] .
$$

In the context of the paper, this is expressed as:

$$
S_{r 1936}-S_{r 1923}=(\rho-1) v_{r 1923}+\left[v_{r 1936}+\rho(1-\rho) \varepsilon_{r 1922}\right] .
$$

30 Davis and Weinstein, "Bones" and "A Search"; Brakman et al., "The strategic."

31 Concerning the validity of this assumption, see footnote 37. 
If we have a valid instrument for the measure of the shock of the earthquake (Sr1923-Sr1922), which serves as Vij1923, we can estimate equation (5). ${ }^{32}$ That is, the equation for estimation is:

$$
S_{r 1936}-S_{r 1923}=(\rho-1)\left(S_{r 1923}-S_{r 1922}\right)+e_{r t} .
$$

In this model, if $\rho=1$, all shocks are permanent and the industrial growth of the areas follows a random walk. If $\rho=0$, the shocks are not persistent at all. If $0<\rho<1$, the shocks are persistent for some time, but will dissipate in the long run. Magnitude of $\rho$ indicates the speed at which the influence of a temporary shock is dissipated. ${ }^{33}$

In addition, given the difference in the recovery process across industries that we observed in the previous section, we use another specification that allows for difference in $\rho$ by industry. That is:

$$
\operatorname{Sir} 1936_{-}-\operatorname{Sir} 1923=\left(\rho_{i}-1\right)\left(\operatorname{Sir}_{1923}-\operatorname{Sir}_{1922}\right) * \operatorname{INDUSTRY} Y_{i}+e_{i r t},
$$

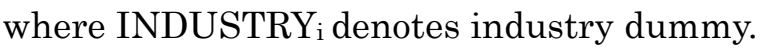

For estimating equations (6) and (7), we compiled the ward- and county-level data on industrial workers by industry for the four data points 1915, 1922, 1923, and 1936. As the data on five industries are available for 15 wards and five counties, there are basically 100 observations for each year. However, the numbers of workers were zero in two wards for the textile industry and one ward for the chemical industry, and so we lost three observations. Consequently, 97 observations were available for the empirical analysis.

As the instrumental variable (IV) for the measure of the shock by the earthquake $\left(S_{r 1923}-S_{r 1922}\right)$ to identify $\mathrm{Vr}_{1923}$, we use the ward- and county-level data of the ratio of buildings that were completely burnt or destroyed (BROKEN). To test the power of the IV, we regressed Sr1923 - Sr1922 on BROKEN (Table 9). The coefficient of BROKEN has the right sign and is statistically significant. At the same time, the $\mathrm{R}^{2}$ is sufficiently large. Hence, BROKEN is used as the IV in estimating equation (6). Meanwhile, in order to estimate equation (7), we need as many instruments as the number of industries. For this purpose, we regressed the measure of the shock by the earthquake ( $\left.\operatorname{sir} 1923-\mathrm{Sir}_{1922}\right)$ on BROKEN, industry dummies, and the interaction of BROKEN and the industry dummies (Table 9). Multiplying the coefficients of the interaction by industry dummies, we obtain the measure of the shock for each industry ${ }^{34}$.

\section{Table 9}

In order to control for the policy effect of zoning, we add the variable AREAI. We also control for the trend of the worker share growth by Sr1922 - Sr1915 for equation (6) and by Sir1922 - Sir1915 for equation (7). Finally, we add a variable indicating the density of the workers at the end of 1922, just before the earthquake (DENSITY 1922 ), to control for the congestion effect. DENSITYr1922 is the total number of industrial workers in area $r$ divided by its area.

32 The measure of the shock from the earthquake, $\mathrm{Sr} 1923-\operatorname{Sr} 1922=\varepsilon_{\mathrm{r} 1923}-\varepsilon_{\mathrm{r} 1922}=v_{\mathrm{r} 1923}+(\rho-1) \varepsilon_{\mathrm{r} 1922}$, is correlated with the error term, $\left[v_{\mathrm{r} 1936}+\rho(\rho-1) \varepsilon_{\mathrm{r} 1922}\right]$.

33 Davis and Weinstein, "Bones," and Brakman et al., "The strategic."

34 Davis and Weinstein, "A search." 
The estimation results for equation (6) are reported in Table 10. In column (1), where no control variable is added, the coefficient of Sij1923 - Sij1922, namely $\rho-1$, is fairly close to -1 , although it is significantly different from -1 at the $10 \%$ level. ${ }^{35}$ In columns (2) and (3), we add the density variable and the policy variable. In these cases, the coefficient of $\mathrm{sij}_{1923}-\mathrm{Sij}_{\mathrm{ij} 1922}$ is fairly close to -1 and, furthermore, is not significantly different from $-1 .{ }^{36}$ These results suggest that most of the effect from the earthquake had dissipated by 1936 .

Table 10

We now look at the estimation results for equation (7) in Table $11 .^{37}$ In most cases, the interactions between $\mathrm{Sij} 1923-\mathrm{Sij} 1922$ and the industry dummies are fairly close to -1 , except for the case of the machinery and metal industry. Furthermore, for the industries other than machinery and metal, the coefficients of the interaction terms are not significantly different from -1 , except for the chemical industry in column (3). On the other hand, for the machinery and metal industry, all the coefficients of the interaction terms are significantly different from -1 , and are not significantly different from 0.38 It is also notable that here the zoning coefficient is positive and strongly significant, which indicates that zoning policy substantially affected the spatial distribution of industries. ${ }^{39}$

Table 11

From the estimation results in this section, we can conclude that the impact of the Great Kanto Earthquake on the spatial distribution of industries had basically dissipated by 1936 , but the impact was persistent for the machinery and metal industry. It is notable that this result is consistent with the observation of the descriptive statistics in Table 5.

We now consider the sources of this peculiarity of the machinery and metal industry. The first thing we take into account is the higher growth of that industry in this period. The number of workers for the machinery and metal industry in Tokyo increased 2.52 times from 1922 to 1936, while the total number of industrial workers increased 1.60 times. 40 The high growth of the machinery and metal industry reflected the reconstruction demand after the Earthquake ${ }^{41}$ as well as the boom in the 1930s. It is well known that the boom in the 1930s was led by the development of the machinery

$35 \mathrm{~F}$-value is 3.91.

$36 \mathrm{~F}$-values are 0.640 and 0.775 , respectively.

37 In order to check for spatial autocorrelation, we calculated Moran's I based on the result of column (3). Weak autocorrelation was only observed for the machinery and metal industry (at the 10\% level).

38 Concerning the case of column (3), the F-values for testing whether the coefficients of the interaction terms of Sir1923-Sir1922 with TEXITILE, MACHINERY, CHEMICAL, FOODS and MISCELLANEOUS are 2.47, 12.75, 6.12, 2.39, and 0.06, respectively.

39 The aim of the zoning regulations was to divide the industrial area from the other areas to protect the environment. For the details of the relationship between zoning and industries, see Numajiri and Imaizumi.

40 Ministry of International Trade and Industry, p. 214.

41 A document by the municipal employment agency office states that the labor demand for the machinery industry increased beyond the supply just after the earthquake (Central Employment Agency Office, "Kanto Daishinsai ni okeru Shokugyo Shokai Seiseki”). 
and metal industry. ${ }^{42}$ The growth of the industry was accompanied by an increase in the number of plants. Indeed, the number of machinery and metal plants increased 3.37 times in Tokyo, while that of the total manufacturing plants increased 2.56 times. $^{43}$ This implies that many new plants were established, especially in the machinery and metal industry. Given this fact, the smaller absolute value of $\rho-1$ for the machinery and metal industry may reflect the tendency of new plants to avoid the congestion in Tokyo City, even if the general congestion effect was accounted for by using the variable DENSITY.

To check this possibility, we estimated equation (7), substituting Sir1930 - Sir1923 for Sir1936-Sir1923 to exclude the influence of the high growth of the machinery and metal industry in the 1930s. In this case, the coefficients of the interaction terms of TEXITILE, MACHINERY, CHEMICAL, FOODS, and MISCELLANEOUS are -0.879 , $-0.486,-0.546,-0.871$, and -0.881 , respectively. In other words, the difference between the machinery and metal industry and the other industries is smaller than in the case of 1936. This result suggests that the congestion effect on new plants indeed existed. At the same time, it is also notable that the difference still remains.

Second, we consider a particular feature of the industrial organization. In an article on the development of the machine tool industry in the 1910s in Japan, Sawai pointed out that small and medium-sized machinery and metal industry plants located in Tokyo and Osaka were interlinked with one another through various forms of outsourcing ${ }^{44}$. This observation is supported by a survey on outsourcing in the machinery industry by the Ministry of Commerce and Industry conducted in the middle of the 1930s. 45 The report of the survey states that, "As the machinery industry needs large amounts of fixed capital, the industrial organization is naturally characterized by extensive division of works. Small and medium-sized firms cannot fill various orders with their own equipment, while large firms often prefer outsourcing works or purchasing parts to fixing large amounts of capital in specific equipment." 46

As shown in Panel A of Table 12, machinery firms not only purchased parts from outside suppliers, but also outsourced production processes such as casting, forging, and machine processing. In addition, Panel B indicates the geographic range of outsourcing networks in the machinery industry. In the context of this paper, it is important that the networks were mainly intra-prefecture in the largest cities and the largest machinery clusters, namely Tokyo and Osaka. Indeed, these outsourcing networks were often limited to a county or several wards. We can infer that such outsourcing networks would facilitate establishing new plants, as well as enhancing the competitiveness of existing plants. In this sense, the outsourcing networks are a source of "centripetal forces" of clusters. ${ }^{47}$ Meanwhile, deliberate cooperation between plants was observed in the cluster of the machinery industry. 48 Although the share declined, the absolute number of machinery and metal workers in Tokyo City in 1936 was larger than in 1922.49 One of the reasons for this recovery was the cooperation of existing plants. For example, plant owners in Honjo and Fukagawa wards organized "Honjo Fukagawa Kogyo Fukkokai" (Association for the Industrial Recovery in Honjo and Fukagawa Wards) in

${ }^{42}$ Cha, "Did Korekiyo" and Nakamura, Economic.

43 Ibid.

44 Sawai, "Daiichiji," p.52.

45 Ministry of Commerce and Industry, Kikai Kigu

46 "Shogen" (Preface) in ibid.

47 Fujita et al., The Spatial, chapter 3.

48 Concerning deliberative cooperation in clusters, see Shmitz and Nadvi, "Clustering."

49 For the source, see the note to Table 4. 
September 1923, just after the earthquake, which engaged in such activities as distribution of materials.50 This is further evidence that the cluster mattered for the machinery and metal industry in this period.

These features such as outsourcing networks and deliberate cooperation in clusters are endogenous sources of agglomeration economies and, as such, are the source of the stability of a spatial equilibrium. On the other hand, if a temporary shock changes the spatial distribution of these features, the economy will shift to a new spatial equilibrium. Concerning the case of the machinery and metal industry in Tokyo, the rapid growth of the industry in the suburban counties just after the earthquake arguably strengthened the agglomeration economies there to cause a persistent shift of the spatial distribution of the industry.

Table 12

\section{Concluding Remarks}

The Great Kanto Earthquake in 1923 was truly a great shock to the Japanese economy. Whereas the ratio of the damage from the earthquake to the GNP was around one-third of that from World War II, the damage from the former was concentrated in Tokyo Prefecture and Kanagawa Prefecture, indeed around 40\% of the buildings in Tokyo Prefecture were completely burnt or destroyed. In this paper, we investigate the long-run impact of a temporary shock on the geographic distribution of industries in Tokyo Prefecture using the Great Kanto Earthquake as a natural experiment. This research strategy has three advantages. First, the earthquake is a purely exogenous event. Second, within Tokyo Prefecture, while the temporary shock had large spatial variation, the variation of fundamental conditions was not as large as for the whole of Japan, which may have made the effect of the temporary shock persistent. Finally, we investigate persistence by industry.

It was revealed that the impact of the temporary shock from the Great Kanto Earthquake had basically dissipated by 1936. This result is consistent with the literature that tests the persistence of the impact of temporary shocks, and supports the view that the geographic distribution of economic activity is principally determined by the first nature (Davis and Weinstein 2002, 2008; Brakman et al. 2004). On the other hand, with respect to the machinery and metal industry, once the clusters were damaged by the earthquake, this shock gave a persistent impact on the spatial distribution of workers. This finding suggests the importance of the industrial organization and transaction networks within industries.

\section{References}

Anderton, Charles H. and John R. Carter (2001) "The impact of war on trade: An interrupted time-series study," Journal of Peace Research, 38(4):445-457

Bosker, Maarten, Steven Brakman, Harry Garretsen and Marc Schramm (2007) "Looking for multiple equilibria when geography matters: German city growth and WWII shock," Journal of Urban Economics, 61: 152-169

Brakman, Steven, Harry Garretsen and Marc Schramm (2004) "The strategic bombing of German cities during the World War II and its impact on city growth," Journal of Economic Geography, 4: 201-218.

Cha, Myung Soo (2003) "Did Korekiyo Takahashi rescue Japan from the Great Depression ?" Journal of Economic History, 63(1): 127-144.

Davis, Donald R. and David Weinstein (2002) "Bones, bombs and break points: The

50 Imaizumi, "Shinsai". 
geography of economic activity," American Economic Review, 92: 1269-1289.

Davis, Donald R. and David Weinstein (2008) "A search for multiple equilibria in urban industrial structure," Journal of Regional Science, 48(1): 29-65.

Economic Planning Agency (1965) Kokumin Shotoku Hakusho (White Paper on National Income), 1963 issue, Tokyo: Printing Bureau of Ministry of Finance (in Japanese).

Economic Planning Agency (2001) Kokumin Keizai Keisan Hokoku: Choki Sokyu Suikyu Shuyo Keiretsu (Report on National Accounts from 1955 to 1998), Tokyo: Printing Bureau of Ministry of Finance (in Japanese).

Economic Stabilization Board (1949) Taiheiyo Senso niyoru Wagakuni no Higai Sogo Hokokusho (General Damage Report of the Second World War,) reprinted in Takafusa Nakamura and Masayasu Miyazaki eds. Shiryo Taiheiyo Senso Higai Chosa Hokoku (Damage Survey Report of the Second World War), Tokyo: The University of Tokyo Press (in Japanese).

Evans, William N., Craig Garthwaite and Heng Wei (2008) "The impact of early discharge law on the health of newborns," Journal of Health Economics, 27: 843-870

Fujita, Masahisa, Paul, R. Krugman and Anthony J. Venables (1999) The Spatial Economy: Cities, Regions, and International Trade, Cambridge, MA: MIT Press.

Horiuchi, Ryoichi (1978) Toshi Keikaku to Yotochiikisei (City Planning and Zoning), Tokyo: Nishida Shoten (in Japanese).

Imaizumi, Asuka (2010) "Yoto Chiikisei Donyu ga Tokyofu Kikai Kanren Kogyo Shuseki ni motarashita Eikyo: Toshikeikaku no Koka to Sangyoshuseki (Effects of land-use zoning on agglomeration of machinery industry in Tokyo: Industrial agglomeration under city planning)," Japan Business History Review, 45(3): 31- 56 (in Japanese).

Ishida, Yorifusa (1987) Nihon Kindai Toshi Keikaku no 100 Nen (100 Years History of Modern City Planning in Japan), Tokyo: Jichitai Kenkyusha (in Japanese).

Koshizawa, Akira (1991) Tokyo no Toshi Keikaku (City Planning in Tokyo), Tokyo: Iwanami Shoten (in Japanese).

Miguel, Edward and Gerald Roland (2006) "The long run impact of bombing Vietnam," NBER working papers 11954.

Ministry of Agriculture and Commerce (1921) Kojo Tsuran (Directory of Factories), 1919 issue, reprinted in 1986, Tokyo: Kashiwa Shobo (in Japanese).

Ministry of Commerce and Industry (1936) Kikai Kigu Kogyo Gaochu Jokyo Shirabe (Survey of Outsourcing in the Machinery Industry), Tokyo: Ministry of Commerce and Industry (in Japanese).

Ministry of International Trade and Industry (1961) Kogyo Tokei 50 Nen Shi (History of the Census of Manufactures for 1909-1958), Tokyo: Printing Bureau of the Ministry of Finance (in Japanese).

Nakajima, Kentaro (2008) "Economic Division and Spatial Relocation: The Case of Postwar Japan," Journal of the Japanese and International Economies, 22(3), 383-400.

Nakamura, Takafusa (1983) Economic Growth in Prewar Japan, New Haven: Yale University Press (translated by Robert A. Feldman).

Numajiri, Akinobu (2002) Kojo Ricchi to Toshi Keikaku: Nihon Toshi Keisei no Tokushitsu 1905-1954 (Plant location and city planning : the making of Japanese cities, 1905-1954), Tokyo: Tokyo Daigaku Shuppankai (in Japanese).

Ohkawa, Kazushi, Nobukiyo Takamatsu and Yuzo Yammoto (1974) Kokumin Shotoku (National Income), Tokyo: Toyo Keizai Shinposha (in Japanese).

Okazaki, Tetsuji and Masahiro Okuno-Fujiwara (1999) "Japan's Present-Day Economic 
System and Its Historical Origins," in Tetsuji Okazaki and Masahiro Okuno-Fujiwara eds., The Japanese Economic System and Its Historical Origins, New York: Oxford University Press

Redding, Stephen J., Daniel M. Strum and Nikolaus Wolf (2007) "History and industry location: Evidence from German airports," CEP Discussion Paper No.809.

Social Affairs Bureau, Ministry of Home Affairs (1924) Shinsai Higai Chosa (Survey on the Damage by the Great Kanto Earthquake), Tokyo: Social Bureau of the Ministry of Home Affairs.

Social Affairs Bureau, Ministry of Home Affairs (1926) Taisho Shinsai Shi (Record on the Great Earthquake in Taisho Era), vol.1, Tokyo: Social Affairs Bureau, Ministry of Home Affairs (in Japanese).

Society for Research on the Recovery (1930) Teito Fukko Shi (History of the Recovery of the Imperial Capital), vol.1-3, Tokyo: Society for Research on the Recovery (in Japanese).

Statistics Bureau of the Ministry of Internal Affairs and Communications ed. (2006) Historical Statistics of Japan, New Edition, vol.1, Tokyo: Japan Statistical Association (in Japanese).

Sawai, Minoru (1981)"Daiichiji Sekaitaisen Zengo niokeru Nihon kosakukikai kogyo no honkakuteki tenkai (Full-scale development of the Japanese machine tool industry around the period of WWI), Shakai Keizai Shigaku (Socio-economic History), 47(2): 155-180 (in Japanese).

Shmitz, Hubert and Khalid Nadvi (1999), "Clusitering and Industrialization: Introduction," World Development, 27(9): 1503-1514.

Takebe, Rokuzo (1925) Tokyo Toshi Keikaku no Kihon Mondai: Jukyo, Shogyo oyobi Kogyo Chiiki (Fundamental Issues of the City Planning in Tokyo: Residential, Commercial and Industrial Zones), Tokyo: Bureau of Reconstruction (in Japanese).

Tokyo City Government (1925) Shinsai niyoru Nihon no Sonshitsu (Damage to Japan by the Great Kanto Earthquake), Tokyo: Isseisha (in Japanese).

Tokyo City Government (1932) Teito Fukko Kukakuseiri Shi (Record of Reconstructing. the Imperial Capital and Land Adjustment) vol.1, Tokyo: Tokyo City Government (in Japanese).

Yano, Kenzo (1932) Kojo to Chiikisei (Factories and Zoning), Tokyo: Moriyama Shoten (in Japanese).

\section{Appendix}

To obtain the area of each zone in each ward and county we took the following procedure. First, the city planning map of Tokyo City 51 is scanned into six tiled digital images. Second, the images are rectified 52 into the real world coordinates, i.e. to fit the remaining roads and landmarks on a digital map of Tokyo ${ }^{53}$ found within GIS. Third, a digital zoning map is created by digitizing the shapes of each zone onto the rectified city planning map images. Finally, the digital zoning map is overlaid with the digital map database of ward and county boundaries in $1923^{54}$, and the overlapping areas are

51 Tokyo Toshi-keikaku Chiiki-zu (City Planning Zoning Map of Tokyo), City Planning Office, Bureau of Audit, Tokyo City Government, 1936.

52 Geometric correction using affine transformation

53 Digital Map 25000 [Spatial Data Framework], Geographical Survey Institute of Japan, 2003. A coordinate transformation from a Geodetic Coordinate System into a Plane Rectangular Coordinate System 2001 zone IX on GIS is required in our process. 54 Yuji Murayama, Administrative boundary digital map after the Meiji period 
computed.

(Database), 2007. 
Figure 1 Map of Japan

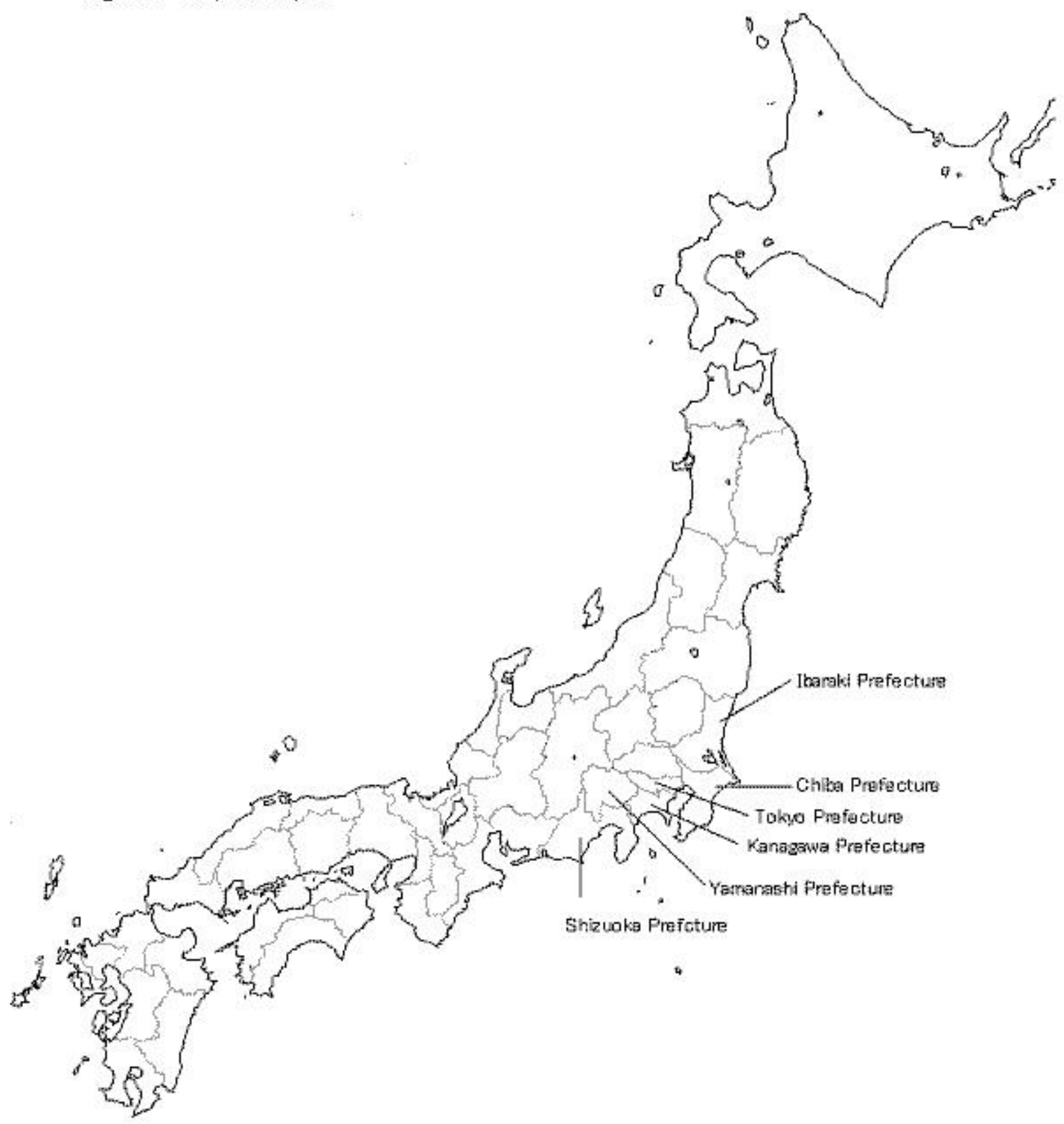




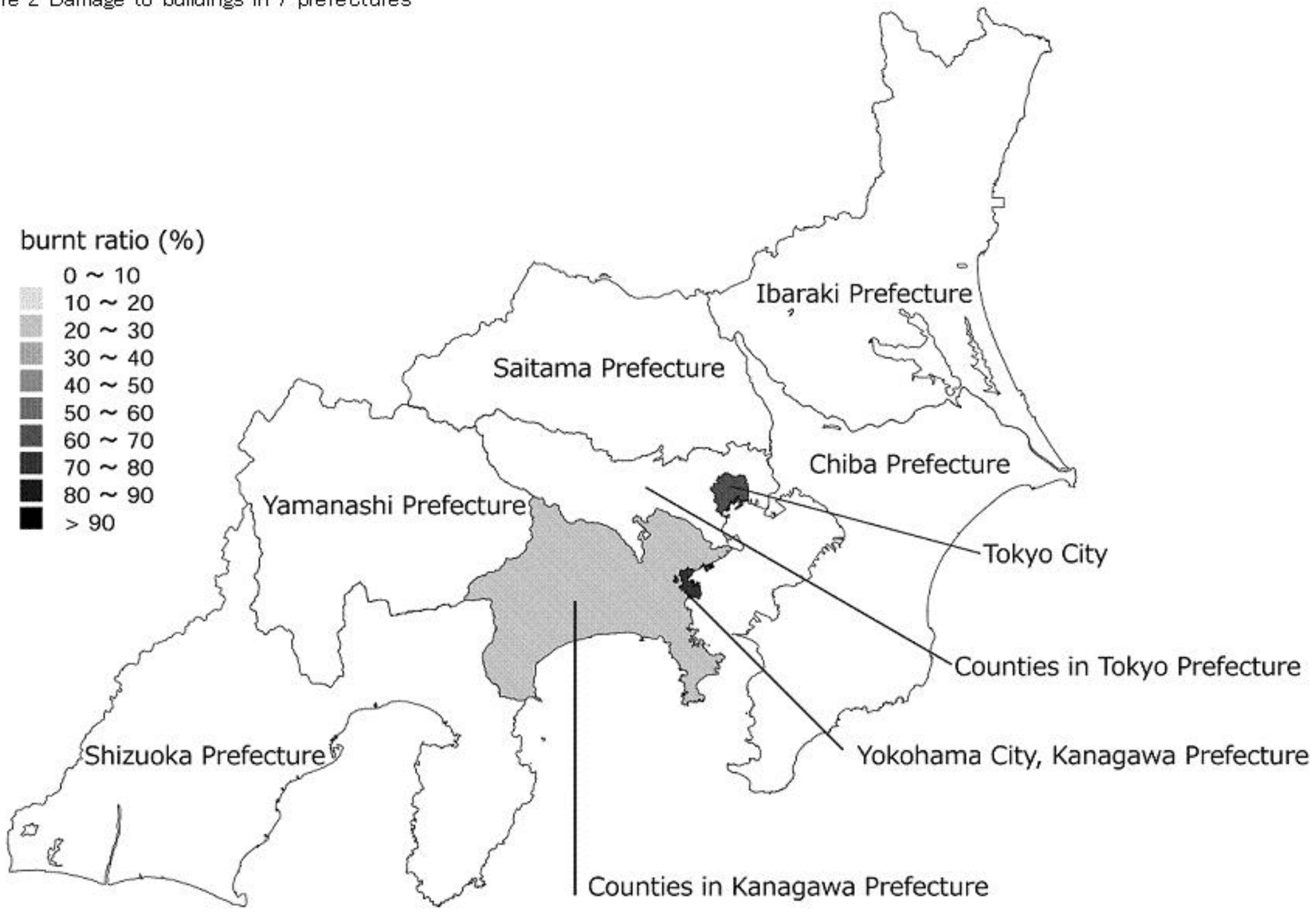


Figure 3 Damage to buildings by ward and county in Tokyo Prefecture

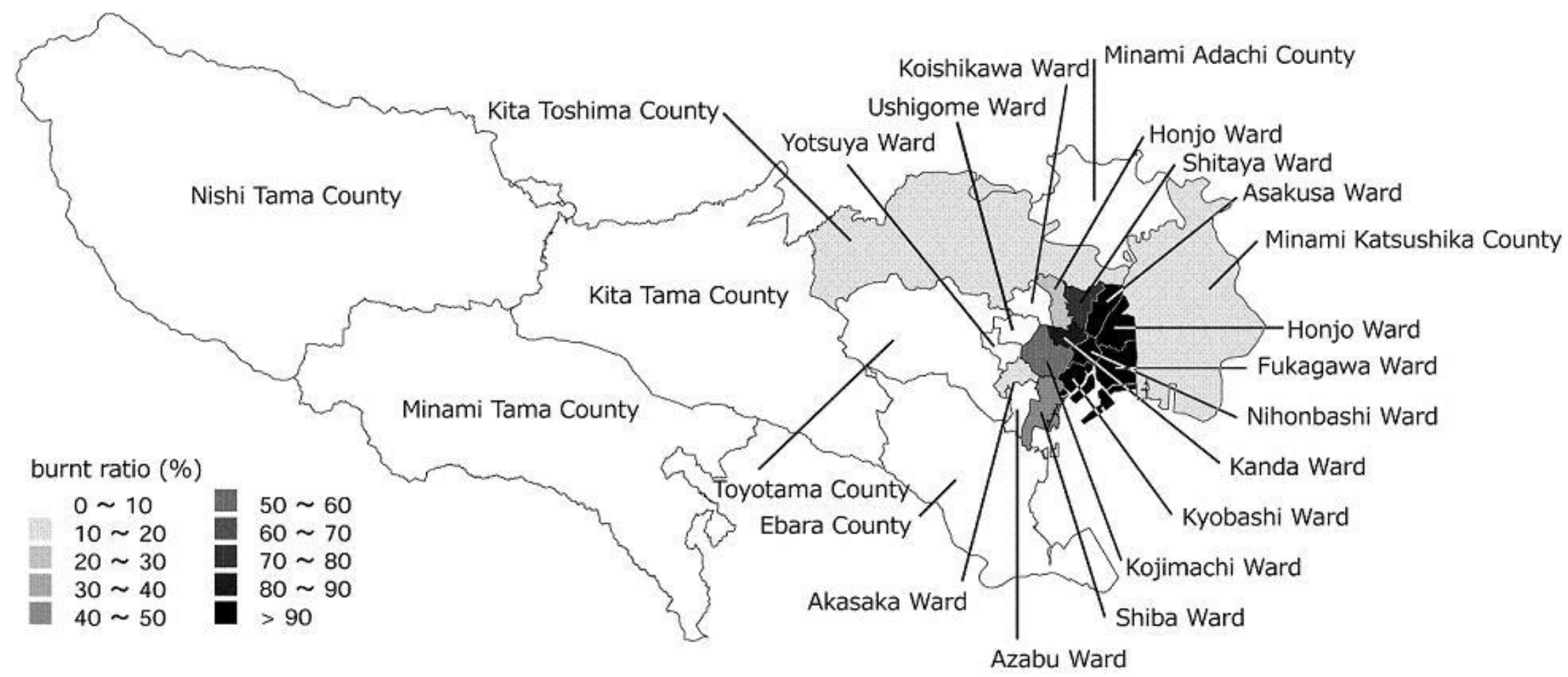




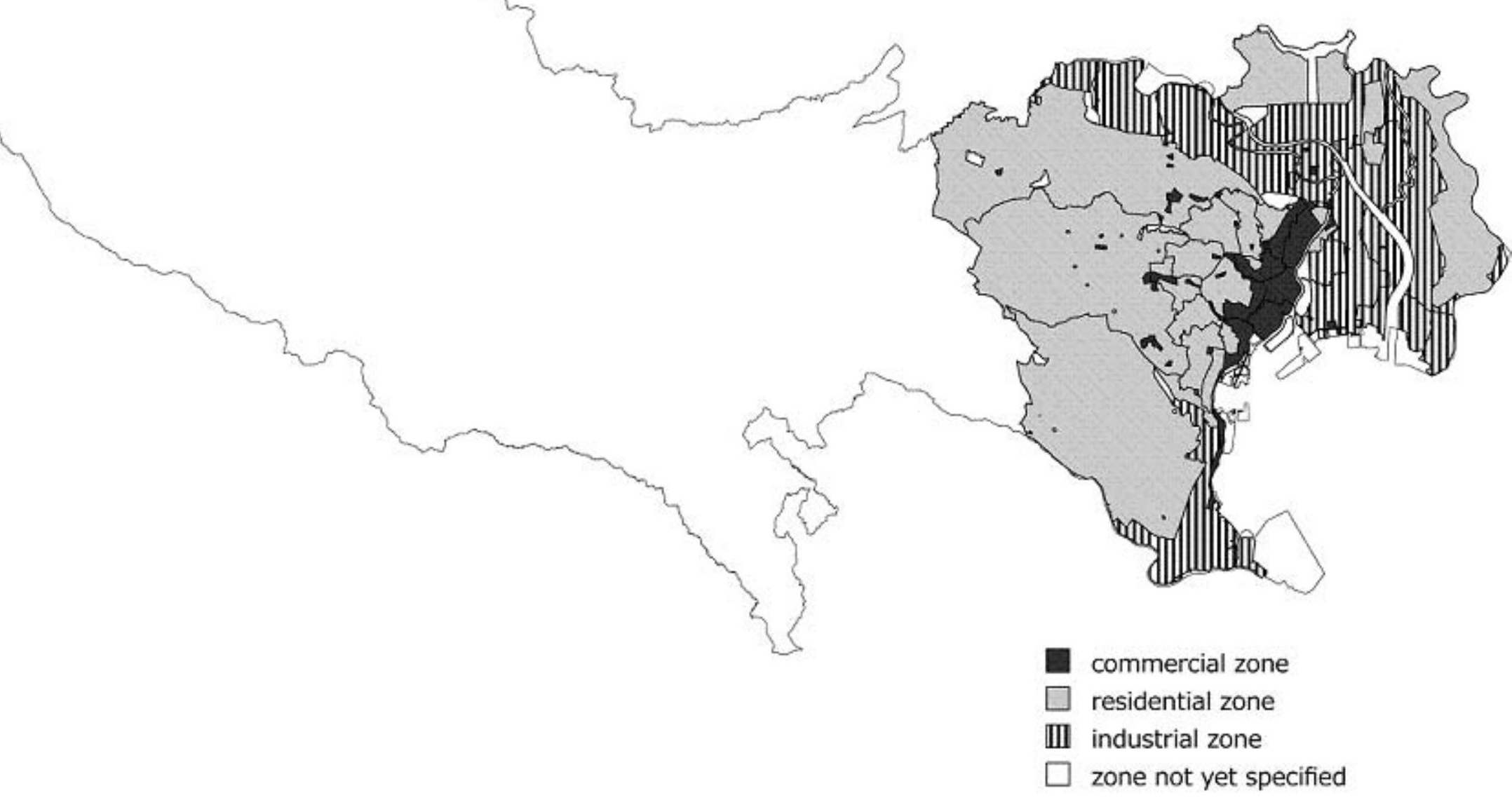


Table 1 Human damage by the Great Kanto Earthquake

\begin{tabular}{lrrrrr}
\hline \hline Prefecture & $\begin{array}{l}\text { Population Just } \\
\text { before the } \\
\text { Earthauake }\end{array}$ & Death & Missing & Total & \multicolumn{2}{c}{$\begin{array}{l}\text { Ratio to the } \\
\text { population }\end{array}$} \\
\hline Total & $11,743,100$ & 91,344 & 13,275 & 104,619 & 0.89 \\
Tokyo & $4,035,700$ & 59,593 & 10,904 & 70,497 & 1.75 \\
$\quad$ Tokyo City & $2,265,300$ & 58,104 & 10,556 & 68,660 & 3.03 \\
$\quad$ The other area & $1,770,400$ & 1,489 & 348 & 1,837 & 0.10 \\
Kanagawa & $1,379,000$ & 29,614 & 2,245 & 31,859 & 2.31 \\
$\quad$ Yokohama City & 446,600 & 21,384 & 1,951 & 23,335 & 5.23 \\
$\quad$ The other area & 932,400 & 8,230 & 294 & 8,524 & 0.91 \\
Chiba & $1,347,200$ & 1,373 & 47 & 1,420 & 0.11 \\
Saitama & $1,353,800$ & 280 & 36 & 316 & 0.02 \\
Shizuoka & $1,626,300$ & 450 & 42 & 492 & 0.03 \\
Yamanashi & 602,000 & 20 & 0 & 20 & 0.00 \\
Ibaraki & $1,399,100$ & 14 & 1 & 15 & 0.00 \\
\hline
\end{tabular}

Source: Tokyo City Government, Shinsai, pp.160-163. 
Table 2 Damage to the buildings by the Great Kanto Earthquake

building, \%

\begin{tabular}{|c|c|c|c|c|c|}
\hline Prefecture & $\begin{array}{l}\text { Number of buildings } \\
\text { just before the } \\
\text { Earthquake }\end{array}$ & $\begin{array}{l}\text { Completely } \\
\text { burnt }\end{array}$ & $\begin{array}{l}\text { Completely } \\
\text { destroyed }\end{array}$ & Total & Percentage \\
\hline Total & $2,284,200$ & 381,090 & 83,819 & 464,909 & 20.4 \\
\hline Tokyo & 826,600 & 311,962 & 16,684 & 328,646 & 39.8 \\
\hline Tokyo City & 483,000 & 300,924 & 4,222 & 305,146 & 63.2 \\
\hline The other area & 343,600 & 11,038 & 12,462 & 23,500 & 6.8 \\
\hline Kanagawa & 274,300 & 68,634 & 46,719 & 115,353 & 42.1 \\
\hline Yokohama & 98,900 & 62,608 & 9,800 & 72,408 & 73.2 \\
\hline The other area & 175,400 & 6,026 & 36,919 & 42,945 & 24.5 \\
\hline Chiba & 262,600 & 478 & 12,894 & 13,372 & 5.1 \\
\hline Saitama & 244,900 & 0 & 4,562 & 4,562 & 1.9 \\
\hline Shizuoka & 289,100 & 16 & 2,241 & 2,257 & 0.8 \\
\hline Yamanashi & 117,000 & 0 & 562 & 562 & 0.5 \\
\hline Ibaraki & 269,700 & 0 & 157 & 157 & 0.1 \\
\hline
\end{tabular}

Source: Tokyo City Government, Shinsai, p.161. 
Table 3 Estimated amount of the damage

\begin{tabular}{|c|c|c|c|c|c|c|}
\hline & \multicolumn{3}{|c|}{ Amount (1,000 yen) } & \multicolumn{3}{|l|}{ Percentage } \\
\hline & 7 prefectures & Tokyo City & Yokohama City & 7 prefectures & Tokyo City & Yokohama City \\
\hline Total & $5,506,386$ & $3,662,163$ & 903,538 & 100.0 & 100.0 & 100.0 \\
\hline Ports & 7,748 & 1,133 & 5,350 & 0.1 & 0.0 & 0.6 \\
\hline Embankments & 39,486 & 0 & 10,140 & 0.7 & 0.0 & 1.1 \\
\hline Roads & 22,660 & 2,018 & 6,839 & 0.4 & 0.1 & 0.8 \\
\hline Bridges & 14,137 & 7,748 & 4,765 & 0.3 & 0.2 & 0.5 \\
\hline Water-works & 13,827 & 10,129 & 3,049 & 0.3 & 0.3 & 0.3 \\
\hline Sewers & 2,312 & 1,172 & 1,140 & 0.0 & 0.0 & 0.1 \\
\hline Ships & 12,215 & 8,065 & 3,735 & 0.2 & 0.2 & 0.4 \\
\hline Equipments for electricity & 43,004 & 39,238 & 3,760 & 0.8 & 1.1 & 0.4 \\
\hline Buildings & $1,874,715$ & $1,112,113$ & 249,007 & 34.0 & 30.4 & 27.6 \\
\hline Household goods & 869,469 & 627,589 & 128,034 & 15.8 & 17.1 & 14.2 \\
\hline Factories & 238,264 & 164,320 & 40,472 & 4.3 & 4.5 & 4.5 \\
\hline Commodities & $2,030,098$ & $1,601,301$ & 427,952 & 36.9 & 43.7 & 47.4 \\
\hline Inventory & 106,637 & 87,340 & 19,297 & 1.9 & 2.4 & 2.1 \\
\hline Others & 231,813 & 0 & 0 & 4.2 & 0.0 & 0.0 \\
\hline
\end{tabular}

Source: Tokyo City Government, Shinsai, p.9 
Table 4 Changes in geographic distribution of industrial workers in Tokyo

\begin{tabular}{|c|c|c|c|c|c|c|c|}
\hline & & \multicolumn{2}{|c|}{ Number of workers } & \multicolumn{3}{|c|}{ Percentage } & \multirow[b]{2}{*}{1936} \\
\hline & & 1922 & 1923 & 1936 & 1922 & 1923 & \\
\hline Total & & 183,521 & 119,012 & 376,718 & 100.00 & 100.00 & 100.00 \\
\hline \multirow{15}{*}{ Tokyo City } & Kojimachi Ward & 2,335 & 1,671 & 4,008 & 1.27 & 1.40 & 1.06 \\
\hline & Kanda Ward & 5,984 & 1,435 & 7,676 & 3.26 & 1.21 & 2.04 \\
\hline & Nihonbashi Ward & 2,075 & 552 & 3,105 & 1.13 & 0.46 & 0.82 \\
\hline & Kyobashi Ward & 13,914 & 2,154 & 12,810 & 7.58 & 1.81 & 3.40 \\
\hline & Shiba Ward & 15,684 & 6,456 & 23,955 & 8.55 & 5.42 & 6.36 \\
\hline & Azabu Ward & 2,567 & 2,486 & 4,019 & 1.40 & 2.09 & 1.07 \\
\hline & Akasaka Ward & 421 & 568 & 844 & 0.23 & 0.48 & 0.22 \\
\hline & Yotsuya Ward & 675 & 834 & 934 & 0.37 & 0.70 & 0.25 \\
\hline & Ushigome Ward & 2,838 & 3,216 & 4,668 & 1.55 & 2.70 & 1.24 \\
\hline & Koishikawa Ward & 6,300 & 6,835 & 6,641 & 3.43 & 5.74 & 1.76 \\
\hline & Hongo Ward & 2,388 & 1,611 & 3,397 & 1.30 & 1.35 & 0.90 \\
\hline & Shitaya Ward & 3,227 & 1,827 & 6,564 & 1.76 & 1.54 & 1.74 \\
\hline & Asakusa Ward & 3,471 & 866 & 9,486 & 1.89 & 0.73 & 2.52 \\
\hline & Honjo Ward & 23,206 & 7,613 & 31,582 & 12.64 & 6.40 & 8.38 \\
\hline & Fukagawa Ward & 13,525 & 2,176 & 12,670 & 7.37 & 1.83 & 3.36 \\
\hline \multirow[t]{5}{*}{ Counties } & Ebara County & 15,284 & 15,205 & 83,059 & 8.33 & 12.78 & 22.05 \\
\hline & Toyotama County & 6,121 & 4,985 & 18,219 & 3.34 & 4.19 & 4.84 \\
\hline & Kitatoshima County & 25,205 & 24,085 & 59,885 & 13.73 & 20.24 & 15.90 \\
\hline & Minami Adachi County & 1,693 & 1,610 & 10,778 & 0.92 & 1.35 & 2.86 \\
\hline & Minami Katushika County & 36,608 & 32,827 & 72,418 & 19.95 & 27.58 & 19.22 \\
\hline
\end{tabular}

Source: Statistical Yearbook of Tokyo City, 1924 issue and 1925 issue; Statistical Yearbook of Industries in Tokyo City, 1938 issue. Note: Shadow indicates the areas whose share declined more than $50 \%$ from 1922 to 1923 . Bold letters sindicate the areas whose share did not recover the half of the decline from 1922 to 1923 , by 1936 
Table 5 Changes in the distribution of industrial workers by industry (percentage)

\begin{tabular}{|c|c|c|c|c|c|c|c|}
\hline \multicolumn{4}{|c|}{$\overline{\text { Textile }}$} & \multicolumn{4}{|c|}{ "Machinery and metal } \\
\hline & & 1922 & 1923 & 1936 & 1922 & 1923 & 1936 \\
\hline Total & & 100.00 & 100.00 & 100.00 & 100.00 & 100.00 & 100.00 \\
\hline \multirow[t]{15}{*}{ Tokyo City } & Kojimachi Ward & 0.08 & 0.10 & 0.01 & 0.52 & 0.20 & 0.28 \\
\hline & Kanda Ward & 0.70 & 0.16 & 0.44 & 1.64 & 1.44 & 0.83 \\
\hline & Nihonbashi Ward & 0.39 & 0.11 & 0.56 & 0.34 & 0.18 & 0.17 \\
\hline & Kyobashi Ward & 0.23 & 0.09 & 0.12 & 9.68 & 1.53 & 3.52 \\
\hline & Shiba Ward & 0.45 & 0.09 & 0.19 & 18.89 & 14.63 & 9.14 \\
\hline & Azabu Ward & 0.33 & 0.36 & 0.34 & 2.66 & 4.58 & 1.50 \\
\hline & Akasaka Ward & 0.06 & 0.09 & 0.02 & 0.22 & 0.49 & 0.11 \\
\hline & Yotsuya Ward & 0.07 & 0.08 & 0.01 & 0.32 & 0.44 & 0.05 \\
\hline & Ushigome Ward & 0.25 & 0.35 & 0.28 & 0.54 & 0.85 & 0.24 \\
\hline & Koishikawa Ward & 1.04 & 1.29 & 1.23 & 2.35 & 3.90 & 0.70 \\
\hline & Hongo Ward & 0.27 & 0.22 & 0.20 & 1.44 & 1.58 & 0.58 \\
\hline & Shitaya Ward & 1.28 & 0.52 & 0.92 & 1.56 & 1.91 & 1.25 \\
\hline & Asakusa Ward & 0.91 & 0.15 & 1.32 & 1.87 & 0.86 & 1.74 \\
\hline & Honjo Ward & 10.72 & 3.55 & 12.16 & 15.77 & 8.79 & 8.36 \\
\hline & Fukagawa Ward & 4.69 & 0.04 & 1.28 & 7.26 & 1.41 & 2.76 \\
\hline \multirow[t]{5}{*}{ Counties } & Ebara County & 5.54 & 6.62 & 8.53 & 10.66 & 18.09 & 31.87 \\
\hline & Toyotama County & 0.95 & 0.93 & 3.02 & 5.89 & 7.06 & 4.68 \\
\hline & Kitatoshima County & 25.38 & 28.24 & 24.93 & 8.02 & 15.30 & 13.41 \\
\hline & Minami Adachi County & 0.57 & 1.33 & 6.94 & 0.26 & 0.16 & 1.39 \\
\hline & Minami Katushika County & 46.12 & 55.69 & 37.48 & 10.11 & 16.61 & 17.43 \\
\hline
\end{tabular}

Source: Statistical Yearbook of Tokyo City, 1924 issue and 1925 issue; Statistical Yearbook of Industries in Tokyo City, 1938 issue. Note: Shadow indicates the areas whose share declined more than $50 \%$ from 1922 to 1923 . Bold letters sindicate the areas whose share did not recover the half of the decline from 1922 to 1923, by 1936 . 
Table 6 Percentage of zones by ward and county

\begin{tabular}{lrrrr}
\hline & Industrial & Commercial & Residential & Not designated \\
\hline Kojimachi Ward & 0.0 & 34.0 & 66.0 & 0.0 \\
Kanda Ward & 0.0 & 84.3 & 15.7 & 0.0 \\
Nihonbashi Ward & 0.0 & 100.0 & 0.0 & 0.0 \\
Kyobashi Ward & 0.0 & 72.7 & 0.0 & 27.3 \\
Shiba Ward & 0.0 & 35.3 & 50.4 & 14.3 \\
Azabu Ward & 0.0 & 1.7 & 97.8 & 0.5 \\
Akasaka Ward & 0.0 & 4.4 & 95.6 & 0.0 \\
Yotsuya Ward & 0.0 & 15.5 & 84.5 & 0.0 \\
Ushigome Ward & 0.0 & 1.5 & 98.5 & 0.0 \\
Koishikawa Ward & 0.0 & 0.9 & 99.1 & 0.0 \\
Hongo Ward & 0.0 & 4.3 & 95.7 & 0.0 \\
Shitaya Ward & 0.8 & 47.5 & 50.6 & 1.1 \\
Asakusa Ward & 5.0 & 81.0 & 14.0 & 0.0 \\
Honjo Ward & 68.7 & 2.9 & 15.9 & 12.5 \\
Fukagawa Ward & 82.6 & 2.8 & 0.0 & 14.6 \\
Ebara County & 21.8 & 1.3 & 75.8 & 1.2 \\
Toyotama County & 0.0 & 1.4 & 97.9 & 0.7 \\
Kitatoshima County & 32.3 & 0.9 & 63.8 & 3.0 \\
Minami Adachi County & 45.6 & 0.4 & 43.3 & 10.7 \\
Minami Katushika County & 67.5 & 0.1 & 32.4 & 0.0 \\
\hline
\end{tabular}

Note: see the text. 
Table 7 Basic statistics

\begin{tabular}{lrrrr}
\hline \hline & \multicolumn{1}{c}{ Mean } & \multicolumn{1}{l}{ Stdev } & \multicolumn{1}{l}{ Min } & \multicolumn{2}{c}{ Max } \\
\hline SHARE & 0.045 & 0.051 & 0.001 & 0.270 \\
AREAI & 0.165 & 0.271 & 0.000 & 0.800 \\
BROKEN & 0.417 & 0.380 & 0.011 & 0.932 \\
BURN & 0.312 & 0.372 & 0.000 & 0.959 \\
DEATH & 0.014 & 0.039 & 0.000 & 0.181 \\
\hline
\end{tabular}


Table 8 Interruption in the level and slope of worker share by the Great Kanto Earthquake

\begin{tabular}{|c|c|c|c|c|c|c|}
\hline \multicolumn{7}{|l|}{ Dependent variable: SHARE } \\
\hline \multicolumn{3}{|l|}{ (1) } & \multicolumn{2}{|l|}{ (2) } & \multicolumn{2}{|c|}{ (3) } \\
\hline$\overline{\text { BROKEN } * \text { AFTER }}$ & -0.0070 & $-1.76 *$ & & & & \\
\hline BROKEN*QUAKETREN[ & 0.0018 & $1.87 *$ & & & & \\
\hline BURN*AFTER & & & -0.011 & $-2.67 * * *$ & & \\
\hline BURN*QUAKETREND & & & 0.003 & $3.24 * * *$ & & \\
\hline DEATH*AFTER & & & & & -0.143 & $-2.35 * *$ \\
\hline DEATH*QUAKETREND & & & & & 0.036 & $2.74 * * *$ \\
\hline$\overline{R-s q}$ & 0.902 & & 0.903 & & 0.904 & \\
\hline Obs. & 360 & & 360 & & 360 & \\
\hline \multicolumn{7}{|l|}{ Dependent variable: SHARE } \\
\hline & ) & & (5) & & & \\
\hline$\overline{\text { BROKEN*AFTER }}$ & -0.010 & $-1.96 *$ & & & & \\
\hline BROKEN*QUAKETREN[ & 0.002 & 1.54 & & & & \\
\hline BURN*AFTER & & & -0.015 & $-2.69 * * *$ & & \\
\hline BURN*QUAKETREND & & & 0.003 & $2.79 * * *$ & & \\
\hline DEATH*AFTER & & & & & -0.199 & $-2.85 * * *$ \\
\hline DEATH $* Q U A K E T R E N D$ & & & & & 0.031 & $2.33 * *$ \\
\hline AREAI & 0.022 & 1.07 & 0.023 & 1.14 & 0.025 & 1.23 \\
\hline $\mathrm{R}-\mathrm{sq}$ & 0.903 & & 0.904 & & 0.904 & \\
\hline Obs. & 360 & & 360 & & 360 & \\
\hline
\end{tabular}

Note: Area dummies and area specific time trends are included, although not reported (see the text). Heteroschedasticity robust standard errors are in parentheses.

$* * *$ statistically significant at $1 \%$ level.

** statistically significant at $5 \%$ level.

* statistically significant at $10 \%$ level. 
Table 9 Instrumenting equations

\begin{tabular}{lclrl}
\hline \hline Dependent variable & $\mathrm{s}_{\mathrm{r} 1923}-\mathrm{s}_{\mathrm{r} 1922}$ & \multicolumn{3}{c}{$\mathrm{s}_{\text {ir } 1923-} \mathrm{s}_{\mathrm{ir} 1922}$} \\
\hline $\mathrm{s}_{\mathrm{r} 1922-} \mathrm{s}_{\mathrm{r} 1915}$ & 0.036 & $(0.075)$ & & \\
$\mathrm{s}_{\text {ir1922- }} \mathrm{s}_{\mathrm{ir} 1915}$ & & & 0.005 & $(0.078)$ \\
BROKEN & -1.839 & $(0.075) * * *$ & & \\
BROKEN*TEXITILE & & & -2.373 & $(0.368) * * *$ \\
BROKEN*MACHINERY & & & -1.487 & $(0.366) * * *$ \\
BROKEN*CHENICAL & & -1.889 & $(0.361) * * *$ \\
BROKEN*FOODS & & -1.866 & $(0.359) * * *$ \\
BROKEN*MISCELLANEOUS & & -1.626 & $(0.364) * * *$ \\
TEXITILE & & 0.401 & $(0.218) *$ \\
MACHINERY & & 0.493 & $(0.205) * *$ \\
CHENICAL & & 0.348 & $(0.205) *$ \\
FOODS & & 0.641 & $(0.208) * * *$ \\
MISCELLANEOUS & & 0.734 & $(0.209) * * *$ \\
Constant & & & \\
\hline Number of obs. & 97 & 97 & \\
$\mathrm{R}^{2}$ & 0.565 & 0.664 & \\
\hline
\end{tabular}

Note: Heteroschedasticity robust standard errors are in parentheses.

$* * *$ statistically significant at $1 \%$ level.

** statistically significant at $5 \%$ level.

* statistically significant at $10 \%$ level. 
Table 10 Test on the persistence of the effect of the Great Kanto Earthquake

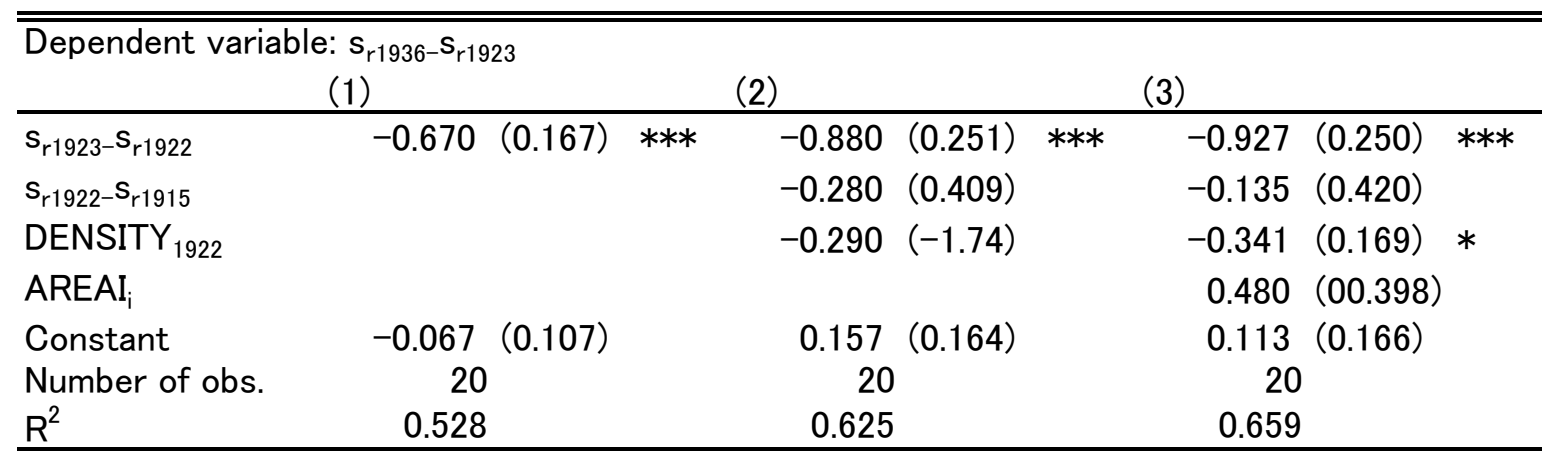

Note: Heteroschedasticity robust standard errors are in parentheses.

$* * *$ statistically significant at $1 \%$ level.

* statistically significant at $10 \%$ level. 
Table 11 Test on the persistence of the effect of the Great Kanto Earthquake by industry

\begin{tabular}{|c|c|c|c|c|c|c|}
\hline Dependent variable: $s_{\text {ir1923- }} s_{\text {ir1936 }}$ & $(1)$ & & (2) & & (3) & \\
\hline$\overline{\left(s_{\text {ir1923- }} s_{\text {ir1922 }}\right) * T E X I T I L E}$ & $-0.766(0.149)$ & $* * *$ & $-0.846(0.169)$ & $* * *$ & $-0.864(0.183)$ & $* * *$ \\
\hline$\left(s_{\text {ir1923- }} s_{\text {ir1922 }}\right) *$ MACHINERY & $-0.189(0.227)$ & & $-0.261(0.270)$ & & $-0.302(0.261)$ & \\
\hline$\left(s_{\text {ir1923- }} s_{\text {ir1922 }}\right) *$ CHEMICAL & $-0.578(0.171)$ & $* * *$ & $-0.618(0.208)$ & $* * *$ & $-0.638(0.231)$ & $* * *$ \\
\hline$\left(s_{\text {ir } 1923-s_{\text {ir } 1922}}\right) *$ FOODS & $-0.729(0.174)$ & $* * *$ & $-0.841(0.190)$ & $* * *$ & $-0.876(0.207)$ & $* * *$ \\
\hline$\left(s_{\text {ir } 1923-} s_{\text {ir1922 }}\right) *$ MISCELLANEOUS & $-0.924(0.311)$ & $* * *$ & $-1.064(0.322)$ & $* * *$ & $-1.117(0.354)$ & $* * *$ \\
\hline$S_{\text {rj1922- }} S_{\text {ir } 1915}$ & & & $-0.099(0.130)$ & & $-1.003(0.133)$ & \\
\hline DENSITY $_{1922}$ & & & $-0.196(0.102)$ & $*$ & $-0.291(0.108)$ & $* * *$ \\
\hline AREAI $_{\mathrm{i}}$ & & & & & $0.870(0.287)$ & $* * *$ \\
\hline Constant & $-0.059(0.092)$ & & $0.143(0.118)$ & & $0.077(0.112)$ & \\
\hline Number of obs. & 97 & & 97 & & 97 & \\
\hline $\mathrm{R}^{2}$ & 0.409 & & 0.444 & & 0.498 & \\
\hline
\end{tabular}

Note: Heteroschedasticity robust standard errors are in parentheses.

*** statistically significant at $1 \%$ level.

* statistically significant at $10 \%$ level. 
Table 12 Organization of machinery industry (1934)

A. Extent of outsourcing

\begin{tabular}{lrr}
\hline \hline & 1,000 yen & \multicolumn{1}{c}{$\%$} \\
\hline Production & 661,300 & 100.0 \\
Total & 163,519 & 24.7 \\
Outsourcing works & 84,247 & 12.7 \\
Casting & 22,951 & 3.5 \\
Making wooden forms & 1,045 & 0.2 \\
Machine processing & 25,244 & 3.8 \\
Sheet processing & 4,339 & 0.7 \\
Forging & 4,108 & 0.6 \\
Heat treatment & 460 & 0.1 \\
Plating & 1,046 & 0.2 \\
Other processes & 25,054 & 3.8 \\
Purchasing parts & 79,271 & 12.0 \\
\hline
\end{tabular}

B. Location of suppliers' customers (\%)

\begin{tabular}{lrr}
\hline \hline Location of & $\begin{array}{l}\text { The same } \\
\text { prefecture }\end{array}$ & \multicolumn{2}{c}{$\begin{array}{l}\text { Other } \\
\text { prefectures }\end{array}$} \\
\hline Total & 53.6 & 46.4 \\
Tokyo Prefecture & 82.1 & 17.9 \\
Kanagawa Prefecture & 7.7 & 92.3 \\
Aichi Prefecture & 61.2 & 38.8 \\
Osaka Prefecture & 87.4 & 12.6 \\
Hyogo Prefecture & 48.5 & 51.5 \\
Hiroshima Prefecture & 60.5 & 39.5 \\
Fukuoka Prefecture & 85.6 & 14.4 \\
\hline
\end{tabular}

Source: Ministry of Commerce and Industry, Kikai Kigu, p.Vi, p.6. 